\title{
Quantitative and Controllable Growth of Carbon Nanotubes on Silicon Carbide Particles Via Chemical Vapor Deposition
}

\author{
Huiling Jin ${ }^{1}$, Jia Jianjun ${ }^{2}$, Yishi Su${ }^{1}$, Shisheng Li $^{1}$, Qiubao Ouyang ${ }^{1}$, , Di Zhang ${ }^{1}$ \\ ${ }^{1}$ State Key Laboratory of Metal Matrix Composites, Shanghai Jiao Tong University, Shanghai, China \\ ${ }^{2}$ Shanghai Institute of Technical Physics, Chinese Academy of Sciences, Shanghai, China
}

Email address:

oyqb@sjtu.edu.cn (Qiubao Ouyang)

${ }^{*}$ Corresponding author

\section{To cite this article:}

Huiling Jin, Jia Jianjun, Yishi Su, Shisheng Li, Qiubao Ouyang, Di Zhang. Quantitative and Controllable Growth of Carbon Nanotubes on Silicon Carbide Particles Via Chemical Vapor Deposition. International Journal of Mechanical Engineering and Applications. Vol. 4, No. 6, 2016, pp. 249-253. doi: 10.11648/j.ijmea.20160406.16

Received: October 16, 2016; Accepted: December 19, 2016; Published: January 19, 2017

\begin{abstract}
Carbon nanotube (CNT) and silicon carbide particles ( $\mathrm{SiCp}$ ) can work together as a double-scale hybrid reinforcement for new metal matrix composites. In this paper, nano nickel (Ni) particle catalyst was precipitated by carbamide to achieve uniform dispersion on micron SiCp. And then a CNT-covered SiCp hybrid was synthesized by a conventional Chemical Vapor Deposition (CVD) method. We found that the content of Ni catalyst has great effects on the size and production of CNT. The yield of CNT reached $20.73 \mathrm{wt} . \%$ with $5.0 \mathrm{wt} . \% \mathrm{Ni}$ under the condition of $923 \mathrm{~K}$ and $1 \mathrm{~h}$ for CVD process. The diameter and average length of the as-grown CNT are $20 \sim 30 \mathrm{~nm}$ and $3 \mu \mathrm{m}$, respectively. Meantime, the chemistry during the controllable growth of CNT was analyzed on the basis of experimental results.
\end{abstract}

Keywords: Carbon Nanotube, Silicon Carbide Particles, Chemical Vapor Deposition, Controllable Growth

\section{Introduction}

Interest in CNT reinforced metal matrix composites (MMCs) has been motivated among research groups since the first discovery by Iijima [1]. Owing to its low density, high aspect ratio, elastic modulus and mechanical strength [2-4], $\mathrm{CNT}$ is predicted as an ideal reinforcement for aluminum matrix composites (AMCs), which have been widely applied in aerospace, defense and petrochemical industries. However, due to the strong intrinsic van der Waals force between nano tubes, CNT tends to easily entangle and agglomerate with each other in the matrix materials. The CNT clusters can greatly damage the properties of composites. Kuzumaki [5] fabricated CNT/Al composites by hot-pressing and hot-extrusion, however, they found that the tensile strength of $\mathrm{CNT} / \mathrm{Al}$ composite is much lower than the theoretical estimation. They observed the interface between CNT and Al under transmission electron microscope, and no reaction products within the CNT/Al interface are observed. They concluded that the inconsistency between the experiment and theoretical estimation may be caused by the nonhomogeneous dispersion of nanotubes in $\mathrm{Al}$ matrix. Hence, higher purification and more homogeneous dispersion of CNT are necessary for the enhancement of composites reinforced by CNT. Extensive researches have been performed to get CNT better dispersed, such as ultrasonic s dispersion method, molecular hybrid method, surfactant method, and high-energy ball-milling method [6-10]. Though they have achieved some improvements, but the results are far from satisfaction because they cannot disperse CNT in microscale or even destroy the surface of CNT [11]. Therefore, it is a big challenge to achieve the homogeneous dispersion of CNT into a metal matrix without damaging its structural integrity.

Introducing micro-sized particle as a carrier by chemical vapor deposition (CVD) is a novel solution to realize the uniform dispersion of CNT in metal matrix. And this method, without the damage of CNT, has been recognized to be more convenient than those methods mentioned above $[12,13]$. But until now, researches still focus on the matrix powder to disperse nanotubes, and then to fabricate composites directly, such as $\mathrm{CNT} / \mathrm{Al}_{2} \mathrm{O}_{3}, \mathrm{CNT} / \mathrm{Al}$ and $\mathrm{CNT} / \mathrm{Cu}$ composite [14-16]. In this paper, we offer an efficient way to produce CNT on the surface of micro-sized $\mathrm{SiC}$ particle ( $\mathrm{SiCp}$ ). We try to combine 
the merit of nano-sized CNT and micro-sized SiCp together to form a hybrid reinforcement-SiCp(CNT), in which $\mathrm{SiCp}, \mathrm{CNT}$ were used as primary, secondary reinforcements respectively in the matrix. In this way, we can achieve uniform dispersion of CNT in the matrix, together with a double-scale hybrid reinforcement. Both SiCp and CNTs are outstanding candidates for MMCs, so this new type of nano/micro-scale hybrid structure can have a remarkable effect on MMCs. Our previous works have made some improvements [17, 18]. But there are few reports about the relationship between the content of catalyst and CVD conditions. In this paper, systematic studies have been carried out to find out the effects of the content of Ni catalyst on the morphology and the yield of the CNTs.

\section{Experimental Procedure}

Figure 1 shows the flow chart of the preparation of $\mathrm{SiCp}(\mathrm{CNT})$ hybrid. Firstly, $\mathrm{Ni}\left(\mathrm{NO}_{3}\right)_{2} \bullet 6 \mathrm{H}_{2} \mathrm{O}(3 \mathrm{~mol} / \mathrm{L})$ and the commercial $\operatorname{SiCp}(7 \mu \mathrm{m})$ were mixed in deionized water to reach different mass ratios of $\mathrm{Ni}$ : $\operatorname{SiCp}(2.5$ wt.\%, 5.0 wt.\%, 7.5 wt.\%, 10.0 wt.\%). Subsequently, $12 \mathrm{~mol} / \mathrm{L}$ of $\mathrm{CO}\left(\mathrm{NH}_{2}\right)_{2}$ solution was gradually added to the mixture under constantly magnetic stirring. Finally, binary colloid $\left(\mathrm{Ni}(\mathrm{OH})_{2} / \mathrm{SiCp}\right)$ was obtained, and the reaction mechanism is shown as below:

$$
\begin{gathered}
\mathrm{CO}\left(\mathrm{NH}_{2}\right)_{2}+3 \mathrm{H}_{2} \mathrm{O} \stackrel{>333 \mathrm{~K}}{\longrightarrow} \mathrm{CO}_{2} \uparrow+2 \mathrm{NH}_{3} \cdot \mathrm{H}_{2} \mathrm{O} \\
\mathrm{NH}_{3} \cdot \mathrm{H}_{2} \mathrm{O} \longrightarrow \mathrm{NH}^{4+}+\mathrm{OH}^{-} \\
\mathrm{Ni}^{2+}+2 \mathrm{OH}^{-} \longrightarrow \mathrm{Ni}(\mathrm{OH})_{2} \downarrow
\end{gathered}
$$

When the supernatant became colorless after reaction, the colloid was filtered, and then dried at $393 \mathrm{~K}$ for $12 \mathrm{~h}$ under vacuum environment and calcined at $673 \mathrm{~K}$ in argon (Ar) atmosphere for $2 \mathrm{~h}$. After all of these processes, fine $\mathrm{NiO} / \mathrm{SiCp}$ precursor was obtained. The as-prepared powders were then loaded on a flat quartz plate in an electrical furnace. When the temperature reached $673 \mathrm{~K}$ in the flow of Ar, hydrogen $\left(\mathrm{H}_{2}\right)$ was fed to reduce the $\mathrm{NiO}$ particle at $673 \mathrm{~K}$ for another $2 \mathrm{~h}$. After then, CNTs were synthesized by introducing a mixture flow of $\mathrm{CH}_{4} / \mathrm{H}_{2} / \mathrm{Ar}$ (1:1:4 in flow rate) into the reactor at 923 $\mathrm{K}$ for $1 \mathrm{~h}$. Finally, the system was cooled down to the ambient temperature in Ar. After the CVD process, the yield of CNT can be calculated by the following equation:

$$
\text { CNT (wt.\%) }=\left(\mathrm{W}_{1}-\mathrm{W}_{2}\right) / \mathrm{W}_{1} \times 100 \%
$$

where $\mathrm{W}_{1}$ is the weight of the $\mathrm{Ni} / \mathrm{SiCp}(\mathrm{CNT})$ hybrid synthesized by CVD and $\mathrm{W}_{2}$ refers to the weight of the $\mathrm{Ni} / \mathrm{SiCp}$ catalyst after the reduction of $\mathrm{H}_{2}$. Each experiment result was obtained from at least three samples.
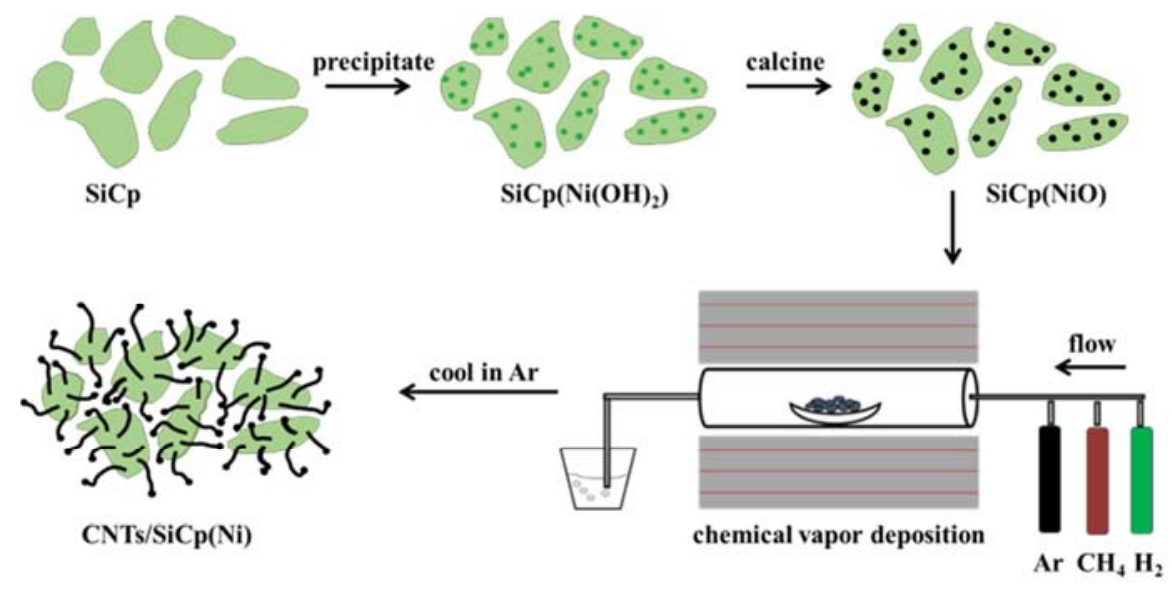

Figure 1. Illustration of in-situ growth of carbon nanotubes on surfaces of silicon carbide particles.

Raman spectrums (RAM, Senterra R200-L, excitation wavelength: $532 \mathrm{~nm}$ ) of the samples were performed to identify the structure of the nano materials. The microstructure of the carbon materials was characterized by Scanning Electron Microscope (SEM) apparatus (Nova Nano SEM NPE 218) and high resolution transmission electron microscope (HRTEM, JEOL 2010F).

\section{Results and Discussion}

The decomposition of $\mathrm{CO}\left(\mathrm{NH}_{2}\right)_{2}$ at $363 \mathrm{~K}$ can slow down the release of hydroxyl $\left(\mathrm{OH}^{-}\right)$ions. According to equation (1), $\mathrm{CO}\left(\mathrm{NH}_{2}\right)_{2}$ initially reacted with $\mathrm{H}_{2} \mathrm{O}$ to generate ammonium hydroxide $\left(\mathrm{NH}_{3} \cdot \mathrm{H}_{2} \mathrm{O}\right)$, thus $\mathrm{OH}^{-}$can only be released through the ionization of $\mathrm{NH}_{3} \cdot \mathrm{H}_{2} \mathrm{O}$ (equation (2)). Then, $\mathrm{Ni}^{2+}$ begin to react with $\mathrm{OH}^{-}$to form $\mathrm{Ni}(\mathrm{OH})_{2}$ (equation (3)) on the surface of SiCp. The above processes can prevent the quick formation of large nickel particles [19-21].

Figure 2a presents the morphology of the irregular SiCp $(\sim$ $7 \mu \mathrm{m})$. And Figure 2c, d, e, f show the microstructure of $\mathrm{Ni}$ particles prepared by carbamide at different content of $\mathrm{Ni}$. It is found that active nickel particles in nano-size are well-dispersed on the surface of SiCp with the content of 2.5 wt.\% Ni (Figure 2c) and 5.0 wt.\% Ni (Figure 2d). And it is obvious that most $\mathrm{Ni}$ particles are homogeneously dispersed with sizes no more than $30 \mathrm{~nm}$. The nano nickel particles, which were precipitated by $\mathrm{CO}\left(\mathrm{NH}_{2}\right)_{2}$, provided an desirable condition for the growth of CNT in the following CVD process. In Figure 2e, when the content of $\mathrm{Ni}$ is $7.5 \mathrm{wt} . \%$, bigger Ni particles begin to appear in the picture. And with the 
content of 10 wt.\% Ni (Figure 2f), the SEM images are full of big Ni particles, some of which are almost in the size of 100 nm.

In addition, the energy spectrum diagram in Figure $2 b$ demonstrates that high purification, and well-dispersed $\mathrm{Ni}$ particles were successfully obtained. Apparently, no agglomeration of Ni particles is observed, so it is effective to inhibit the formation of $\mathrm{Ni}$ clusters on the $\mathrm{SiCp}$ surface by using $\mathrm{CO}\left(\mathrm{NH}_{2}\right)_{2}$ as the precipitant, making the CNT grown on this catalyst relatively small and uniform in diameter. But high content of $\mathrm{Ni}$ will cause the catalyst in bigger size.
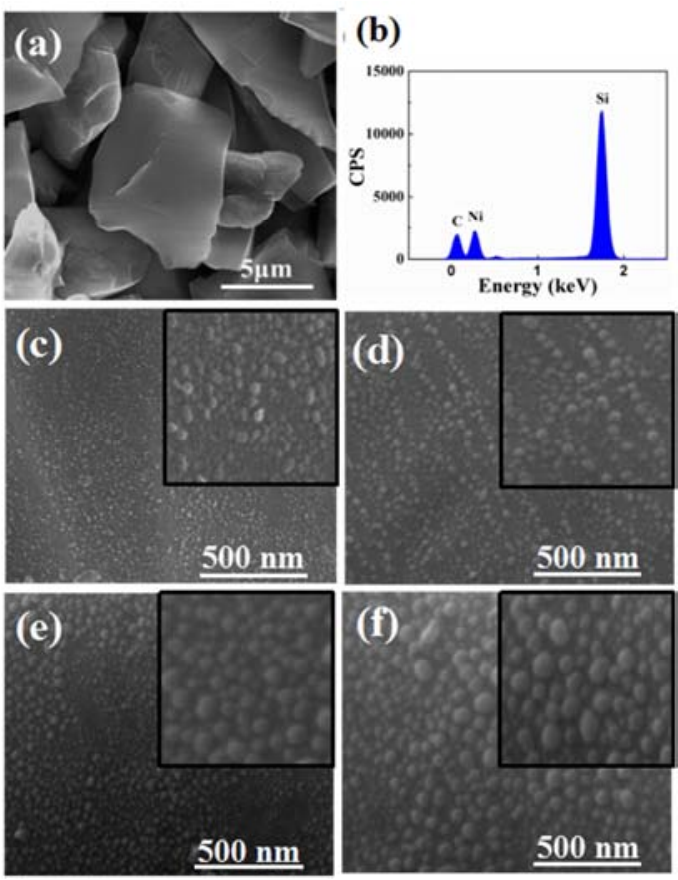

Figure 2. (a) Morphology of SiCp, (b) EDS of SiCp(5.0wt.\% Ni) catalyst in (d), (c) $2.5 \mathrm{wt} \% \mathrm{Ni} / \mathrm{SiCp}$, (d) $5.0 \mathrm{wt} \% \mathrm{Ni} / \mathrm{SiCp}$, (e) $7.5 \mathrm{wt} \% \mathrm{Ni} / \mathrm{SiCp}$, (f) 10.0 $w t \% \mathrm{Ni} / \mathrm{SiCp}$.

The effect of $\mathrm{Ni}$ proportion among the SiCp (2.5wt.\%, $5.0 \mathrm{wt} . \%, 7.5 \mathrm{wt} . \%, 10.0 \mathrm{wt} . \%)$ on the yield of CNT was investigated systematically, as presented in Figure 3. We can observe from Figure 3 that, initially, the yield of CNT increased with the increasing of $\mathrm{Ni}$, then peaked at $20.73 \mathrm{wt} . \%$ with $5.0 \mathrm{wt} . \% \mathrm{Ni}$. Further increase of $\mathrm{Ni}$ content no longer helped to increase the production of CNT, but decreased.

The SEM images of the as-prepared $\mathrm{SiCp}(\mathrm{CNT})$ are given in Figure 4. Figure 3b represents the SEM image of $2.5 \mathrm{wt} . \%$ $\mathrm{Ni} / \mathrm{SiCp}(\mathrm{CNT})$. Little CNTs are found in the picture, because we can even see the surface of the SiCp under the CNTs. The spherical particles refer to the nano $\mathrm{Ni}$ particles, some of which are not able to in-situ grow CNT. Further study to improve the activity of the catalytic particles need to be carried out. Figure $4 \mathrm{~b}$ shows fully CNT-covered SiCp with 5.0 wt.\% Ni. And the CNTs are about 3 5 $\mu \mathrm{m}$ in length. We can see that the CNTs synthesized at this condition are of great uniform distribution in diameter and also high in yield. This is a significant improvement compared with our previous work in which we can only observe a thin layer of CNTs over SiCp
[23]. It may contribute to the improvement that we increase the reaction time to $1 \mathrm{~h}$. In this way, more carbon can diffuse through the catalyst particles to form longer CNTs. However, it is not the main factor that decides the yield of the as-synthesized CNTs because CNTs with 2.5 wt.\% Ni were also prepared under the same condition. So, it is the content of the catalytic particle that plays an important role in the yield of the CNT. When the content of Ni particles is relatively low, there isn't enough active catalytic particles to in-situ grow CNT. But when the content of Ni particles is more than 5.0 wt.\%, the Ni ions are more likely to congregate, making the $\mathrm{Ni}$ crystals grow bigger and result in CNTs with bigger diameters (as showed in Figure 4c).

It can be observed from Figure $4 \mathrm{~d}$ that when the content of $\mathrm{Ni}$ reached 10wt.\%, some carbon cluster and carbon amorphous occurred, and little CNTs are found in the SEM images. Through analysis, it can be attributed to the reason that when the content of Ni ions was higher during the uniform deposition process, the speed of the nucleation and growth of $\mathrm{Ni}$ particles increased significantly. Besides, with higher content of reduced $\mathrm{Ni}$ particle during the reaction time, it's more likely to form large active metal particles, making CNTs in large diameters. This is in agreement with Ran [22], who reported the catalytic performance of $\mathrm{Ni} / \mathrm{MgO}$ catalysts for controllable synthesis of MWCNTs. The change of Ni contents is related with $\mathrm{Ni}$ mean particle size on the catalyst surface, leading to CNTs in different diameters and yields.

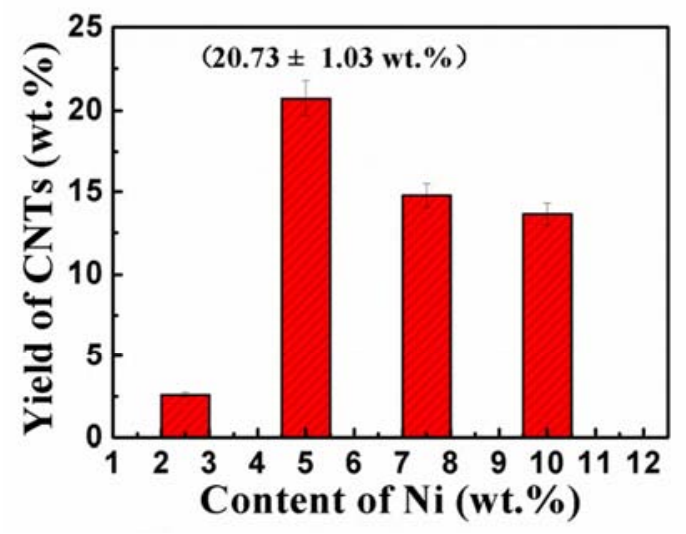

Figure 3. Yield of CNTs with different content of Ni catalyst.
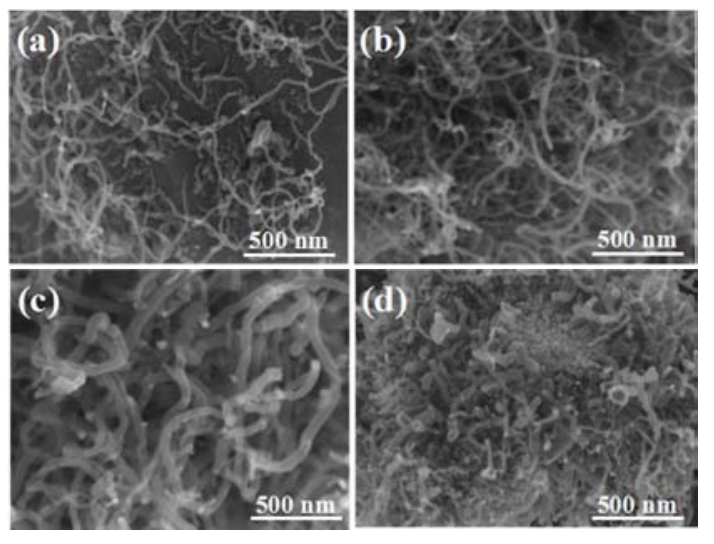

Figure 4. SEM images: (a) CNTs/SiCp $(2.5 w t . \% \mathrm{Ni})$, (b) CNTs/SiCp $(5.0$ wt.\% $\mathrm{Ni}$ ), (c) $\mathrm{CNTs} / \mathrm{SiCp}(7.5 \mathrm{wt} . \% \mathrm{Ni})$, (d) CNTs/SiCp$(10.0 \mathrm{wt} \% \mathrm{Ni})$. 
The Raman spectroscopy (Figure 5a) shows two main bands at around $1340.5 \mathrm{~cm}^{-1}\left(\mathrm{I}_{\mathrm{D}}=921.96\right)$ and $1571.5 \mathrm{~cm}^{-1}\left(\mathrm{I}_{\mathrm{G}}\right.$ $=1204.18)$, which are attributed to D-band and G-band respectively. G-band arises from tangential optical modes E2g of 2D graphite, while D-band intensity is related to the defect status states of MWCNTs [24]. The intensity of $\mathrm{I}_{\mathrm{D}} / \mathrm{I}_{\mathrm{G}}$ was calculated as 0.77 . It suggests that the well-crystallized graphite with little defect states lay in our produced nanomaterials, corresponding with the SEM and HRTEM results.

As for the growth mechanism of CNT, it is widely believed there are two steps: firstly, the hydrocarbon molecules are adsorbed on the catalyst molecules pyrolysis to obtain carbon atoms, and then, the carbon atoms will continuously diffuse to the other side of Ni particles to form CNT. On the basis of Backer model [25], the carbon compounds are decomposed on the surface of the substrate particles, and the precipitation of graphite is followed after the adsorbed carbon is dissolved in the particles to form a supersaturated solution. And the tube will grow via the diffusion of carbon through the catalyst
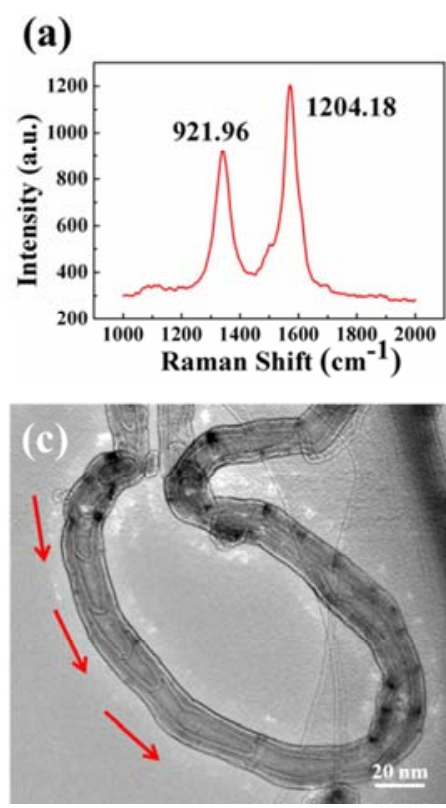

Figure 5. (a) Raman spectrum of CVD grown CNTs with 5.0wt.\% Ni, (b, c) Low magnification of CVD grown CNTs with 5.0wt.\% Ni, (d) HRTEM image of CVD grown CNTs with 5.0wt.\% Ni.

\section{Conclusions}

(1) Nanoscale Ni particles were homogeneously deposited on the surface of $\mathrm{SiCp}$ by using $\mathrm{CO}\left(\mathrm{NH}_{2}\right)_{2}$ solution to obtain binary colloid $\left(\mathrm{Ni}(\mathrm{OH})_{2} / \mathrm{SiCp}\right)$.

(2) $20.73 \mathrm{wt} . \%$ multi-walled CNTs were fabricated via catalytic decomposition of methane with micron 5.0 wt. $\% \mathrm{Ni} / \mathrm{SiCp}$ support at $923 \mathrm{~K}$ for $1 \mathrm{~h}$. When the content of Ni catalyst is relative low, the yield of CNT increases with the increase of $\mathrm{Ni}$ catalyst, and peaked at $5.0 \mathrm{wt} . \% \mathrm{Ni}$. With further increase of $\mathrm{Ni}$ content, the CNT yield began to decrease.

(3) The suggested approach in this work is an effective method to synthesize tube yield controllable MWCNTs. particles.

A more detailed observation of $5.0 \mathrm{wt} \% \mathrm{Ni} / \mathrm{SiCp}(\mathrm{CNT})$ achieved by CVD at $923 \mathrm{~K}$ for $1 \mathrm{~h}$ is depicted by HRTEM, as shown in Figure 5b, c, d. As we can see from Figure 4b, CNTs were bonded on the surface of SiCp (black area). Based on the TEM observations, the as-synthesized CNT have a hollow tubular structure with average diameter of $20 \sim 30 \mathrm{~nm}$ at $923 \mathrm{~K}$, which is consistent with the diameter of nano Ni particle. The average length of CNT is about $3 \mu \mathrm{m}$, with a very high aspect ratio $(\mathrm{L} / \mathrm{D}=100 \sim 150)$. Moreover, no amorphous carbon or carbon granule are found in the figures, and the surfaces of CNTs are both clean and smooth, which demonstrates CNTs are of high purity and the yields of CNTs are calculated accurately. In Figure 5c, we observed the direction (the red arrow) of the carbon diffusion to form the tube during the CVD process. Inserted image in Figure $5 \mathrm{~d}$ is the Inverse Fast Fourier transformed (IFFT) image of CNT, it shows an interlayer spacing of $0.33 \mathrm{~nm}$ for the CVD-grown CNT, which is in accordance with the ideal graphitic interlayer space $(0.34$ $\mathrm{nm})$.

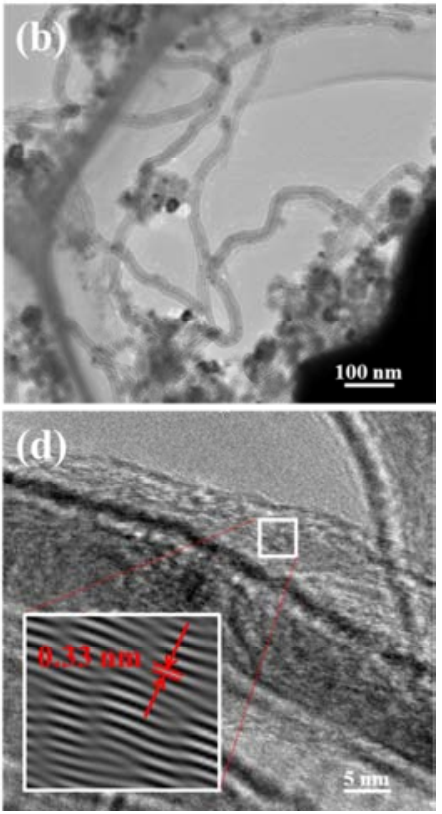

It can be up-scaled to produce large quantity CNT at a low cost. In this way, CNT and SiCp will work together to form a more powerful micro/nano reinforcement for a new type of composite.

\section{Acknowledgements}

The authors sincerely acknowledge the financial support by the National Natural Science Foundation (Nos.51471106, 51501111), the National Basic Research Program (973 Program) (No. 2012CB619600) and the Foundation of Shanghai Science and Technology Committee of China (No. 14DZ2261200). 


\section{References}

[1] S. Iijima, Helical microtubules of graphitic carbon. Nature. 1991; 354: 56-58.

[2] D. B. Miracle. Metal matrix composites - from science to technological significance. Compos Sci Technol. 2005, 65: $2526-2540$

[3] Poncharal P, Wang ZL, Ugarte D, Heer WAd. Electrostatic Deflections and Electromechanical Resonances of Carbon Nanotubes. Science. 1999; 283: 1513-1516.

[4] Yu M-F, Lourie O, Dyer MJ, Moloni K, Kelly TF, Ruoff RS. Strength and breaking mechanism of multiwalled carbon nanotubes under tensile load. Science. 2000; 287: 637-640.

[5] T. Kuzumaki KM, H. Ichinose, and K. Ito. Processing of carbon nanotube reinforced aluminum composite. Journal of Materials Research. 1998; 13: 2445-2449.

[6] Cha SI, Kim KT, Arshad SN, Mo CB, Hong SH. Extraordinary strengthening effect of carbon nanotubes in metal-matrix nanocomposites processed by molecular-level mixing. Advanced Materials. 2005; 17: 1377-1381.

[7] Jiang L, Fan G, Li Z, Kai X, Zhang D, Chen Z, et al. An approach to the uniform dispersion of a high volume fraction of carbon nanotubes in aluminum powder. Carbon. 2011; 49: 1965-1971.

[8] Lin W, Heekyu C, Jae-Min M, Woong L. Mechanical alloying of multi-walled carbon nanotubes and aluminium powders for the preparation of carbon/metal composites. Carbon. 2009; 47: 3427-3433.

[9] Tang Y, Cong H, Zhong R, Cheng H-M. Thermal expansion of a composite of single-walled carbon nanotubes and nanocrystalline aluminum. Carbon. 2004; 42: 3260-3262.

[10] G. Gorrasi et al. Incorporation of carbon nanotubes into polyethylene by high energy ball milling: Morphology and physical properties. Journal of polymer science Part B Polymer Physics.2007; 45: 597-606.

[11] Poirier D, Gauvin R, Drew RAL. Structural characterization of a mechanically milled carbon nanotube/aluminum mixture. Composites Part A: Applied Science and Manufacturing. 2009; 40: 1482-1489.

[12] Praveen Kolla, Chuilin Lai, Srujan Mishra, et.al. CVD grown CNTs within iron modified and graphitized carbon aerogel as durable oxygen reduction catalysts in acidic medium. Carbon. 2014; 79: 518-528.

[13] Christian Hoecker, Fiona Smail, Mark Bajada, et.al. Catalyst nanoparticle growth dynamics and their influence on product morphology in a CVD process for continuous carbon nanotube synthesis. Carbon. 2016; 96: 116-124.

[14] Anup K. Keshri a, Jun Huang b, Virendra Singh. Synthesis of aluminum oxide coating with carbon nanotube reinforcement produced by chemical vapor deposition for improved fracture and wear resistance. Carbon. 2010; 48: 431-442.

[15] Lijie Ci, Zhenyu Ryu, Neng Yun Jin-Phillipp. Investigation of the interfacial reaction between multi-walled carbon nanotubes and aluminum. Acta Mater. 2006; 54: 5367-5375.

[16] Hu Zhang, Jianli Kang, Kaiqiang Qin, Ronglu Sun, Chunsheng Shi, Naiqin Zhao, Zhoun Qiao. Controllable synthesis of carbon nanostructures with high purity and quality directly on copper substrate by a simple CVD process. 2011.

[17] Shisheng Li, Yishi Su, Qiubao Ouyang. In-situ carbon nanotube-covered silicon carbide particle reinforced aluminum matrix composites fabricated by powder metallurgy. Mater. Lett. 2016, 167: 118-121.

[18] Shisheng Li, Yishi Su, Xinhai Zhu, Huiling Jin. Enhanced mechanical behavior and fabrication of silicon carbide particles covered by in-situ carbon nanotube reinforced 6061 aluminum matrix composites. Mater. Design, 2016; 107: 130-138.

[19] Dillen AJV, Geus JW, Hermans LAM, Meijden JVd. In: Proceedings of the sixth international congress. Catalysis. 1977; 2.

[20] Hermans LAM, Geus JW. Interaction Of Nickel Ions With Silica Supports During Deposition-Precipitation. Studies in Surface Science and Catalysis. 1979; 3: 113-130.

[21] Hua YS, Li RC. Different precipitant comparative study of the preparation of nanoscale nickel oxide catalyst. Science and technology information. 2009; 16: 459-462.

[22] Ran M, Chu W, Liu Y, Liu D, Zhang C, Zheng J. Doping effects of manganese on the catalytic performance and structure of $\mathrm{NiMgO}$ catalysts for controllabe synthesis of multi-walled carbon nanotubes. Journal of Energy Chemistry. 2014; 23: 781-788.

[23] Li S, Su Y, Ouyang Q, Zhang D. In-situ carbon nanotube-covered silicon carbide particle reinforced aluminum matrix composites fabricated by powder metallurgy. Materials Letters. 2016; 167: 118-121.

[24] Baro M, Pal AR. One-step grown multi-walled carbon nanotubes with Ni filling and decoration. Journal of Physics D: Applied Physics. 2015; 48: 225303.

[25] He CN, Zhao NQ, Shi CS, Song SZ. An approach for obtaining the structural diversity of multi-walled carbon nanotubes on $\mathrm{Ni} / \mathrm{Al}$ catalyst with low $\mathrm{Ni}$ content. Journal of Alloys and Compounds. 2010; 489: 20-25. 